\title{
Breastfeeding practices and parental employment in Japan
}

\author{
Miki Kobayashi • Emiko Usui
}

Received: 4 October 2013/Accepted: 2 April 2014/Published online: 13 April 2014

(C) The Author(s) 2014. This article is published with open access at Springerlink.com

\begin{abstract}
Much research shows that breastfeeding provides short- and long-term health benefits for both mothers and their children. However, few studies have yet investigated the factors which may promote or inhibit breastfeeding practices in Japan. To fill this research gap, this paper uses data newly gathered in 2012 on breastfeeding initiation and duration for each child of each mother, which enable us to estimate mother fixed-effects models that control for unobserved differences among mothers. Compared to mothers who leave their jobs after childbirth, mothers who return to work within a year after childbirth do not significantly differ in breastfeeding initiation but have a breastfeeding duration which is shorter by 1.654 months. On the other hand, when fathers work under a flextime system after childbirth, breastfeeding initiation is higher, and the duration is longer by 4.418 months. Therefore, letting fathers work under a flextime system would help promote breastfeeding practices in Japan.
\end{abstract}

Keywords Breastfeeding · Maternal employment $\cdot$ Paternal job responsibility · Japan

JEL Classification J13

\section{Introduction}

Abundant evidence has demonstrated the short- and long-term health benefits of breastfeeding for both children and mothers. For children, the benefits of

\footnotetext{
M. Kobayashi

Graduate School of Economics, Kobe University, Kobe 657-8501, Japan

e-mail: mkobayashi@people.kobe-u.ac.jp

E. Usui $(\square)$

Institute of Economic Research, Hitotsubashi University, Kunitachi, Tokyo 186-8603, Japan

e-mail: usui@ier.hit-u.ac.jp
} 
breastfeeding include protection against childhood infectious diseases, decreased risk for both chronic diseases and sudden infant death syndrome (Howie et al. 1990; Beral et al. 2002; Ip et al. 2007; and WHO/UNICEF 2009), a positive association with higher intelligence scores (Borra et al. 2012; McCrory and Layte 2011), and reduced risk for being overweight or obese later on (McCrory and Layte 2012). The health benefits for breastfeeding mothers include reduced postpartum bleeding, contraceptive effect of delays in the resumption of the menstrual cycle, faster shrinking of the uterus, and decreased risk of breast and ovarian cancers. In a global public health recommendation, the World Health Organization (WHO) declared in 1990 that infants should be exclusively breastfed until 6 months of age, with breastfeeding continuing until the child is 2 years of age or more (WHO/UNICEF 1990). Based on this recommendation, the Ministry of Health, Labour and Welfare in Japan has been promoting and supporting breastfeeding by, for example, creating the "Support Guide for Breastfeeding and Weaning" (Ministry of Health, Labour and Welfare 2007) for medical practitioners.

Researchers in many countries have shown that there exists a conflict between breastfeeding and the mothers' return to work after childbirth. Chatterji and Frick (2005), for example, find that for mothers in the US who return to work within 3 months after childbirth, the probability of initiating breastfeeding decreases by $16-18 \%$ and the duration of breastfeeding is shortened by 4-5 weeks. Focusing on the increase in maternity-leave mandates in Canada, Baker and Milligan (2008) find that with every additional month not at work after childbirth, the duration of breastfeeding is prolonged by 2.6 weeks. Other studies that find an incompatibility between maternal employment and breastfeeding include Roe et al. (1999), Haider et al. (2003), and Mandal et al. (2010, 2012) for the US, Gatrell (2007) for the UK, and Cooklin et al. (2008) for Australia.

In Japan, over the past 20 years, approximately $60 \%$ of working women quit their jobs because of pregnancy or childbirth (Cabinet Office, Government of Japan 2012), and only $27.1 \%$ of mothers work when their firstborn child is 1 year old (National Institute of Population and Social Security Research 2010). Although the reason why mothers leave the labor force is to care for children, which goes well beyond breastfeeding, combining work and breastfeeding may be especially challenging for mothers in Japan, because support for breastfeeding in the Japanese workplace has been quite limited. To date, however, very little research conducted in Japan has examined to what extent maternal employment is compatible with breastfeeding practices. To begin with, few studies have investigated associations between breastfeeding duration and mothers' socioeconomic and educational status in Japan (Inoue et al. 2012). Furthermore, previous studies on breastfeeding in countries other than Japan have focused on the compatibility between breastfeeding and maternal employment, but have paid less attention to the effect of fathers' work arrangements on breastfeeding practices. Since mothers may already be overburdened by infant care and domestic chores, fathers' increased time at home may ease their wives' burden and this makes breastfeeding more feasible. For this reason, in this paper we investigate to what extent this linkage exists in Japan.

Until recently, it has not been possible to empirically investigate factors that influence breastfeeding practices in Japan because of data limitations. Three 
national surveys administered by Japan's Ministry of Health, Labour and Welfare collect data on breastfeeding: (1) the National Nutrition Survey on Infants and Preschool Children, (2) the National Growth Survey on Infants and Preschool Children, and (3) the Longitudinal Survey of Babies in Twenty-first Century (Babies born in 2001 and 2010). The first two surveys collect data decennially on infants' feeding methods and foods since 1985 and 1960, respectively. However, the surveys do not collect information on family background characteristics; the first survey lacks data on parents' education and employment status and the number of children in the household, and the second survey lacks data on parents' education and fathers' employment status. The third survey, which samples children born in January and July of 2001 and 2010, does collect information on family background characteristics; it also asks about mothers' breastfeeding practices when their youngest child was 6 months of age. Since the median duration of breastfeeding is about 12 months for women in Japan (see Fig. 1), the length of completed breastfeeding spells is not available for many mothers in this survey. Furthermore, data on mothers' breastfeeding practices are limited to their youngest child, and therefore the sample does not allow an estimation of mother fixed-effects models that could account for the correlation between maternal employment and unobserved maternal characteristics.

To overcome these problems, we use newly gathered data from the 2012 Japanese Longitudinal Survey on Employment and Fertility (LOSEF). The LOSEF collects information not only on parents' socioeconomic status, but also on past fertility history, including data on breastfeeding and changes in parents' employment before and after childbirth for each child. For breastfeeding practices, we have information on (1) breastfeeding initiation, and (2) breastfeeding duration, which is the number of months, if any, that the mother breastfed the child. Using this survey, we examine the factors that influence breastfeeding practices by estimating a logit model for breastfeeding initiation and an OLS model for breastfeeding duration. For both breastfeeding initiation and duration, we also estimate mother fixed-effects models.

We find that breastfeeding tends to be initiated by mothers with a higher level of education, but among mothers who initiate breastfeeding, the duration of breastfeeding does not differ significantly by education. Breastfeeding initiation does not differ by birth order either, but its duration tends to be longer for the

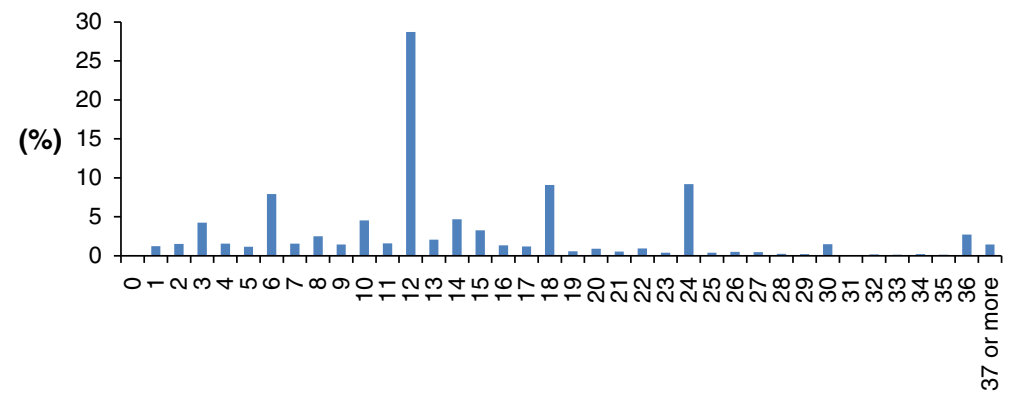

Fig. 1 Number of months of breastfeeding. Data source: LOSEF 
firstborn child. Breastfeeding initiation is higher and the duration is longer for mothers from younger generations, for mothers who give birth to a singleton, and for mothers who give birth at an older age. In Japan, breastfeeding initiation does not significantly differ between mothers who return to work within a year after childbirth and those who leave the job after childbirth, but the breastfeeding duration is shorter by 1.654 months for the former group. However, when fathers work under a flextime system after childbirth, mothers' breastfeeding initiation increases and the duration increases by 4.418 months, indicating that when fathers provide assistance and support in early childrearing, it encourages mothers to initiate and continue breastfeeding. Therefore, allowing fathers to work under a flextime system promote the practice of breastfeeding in Japan.

\section{Data and methods}

\subsection{Data}

We use data from the Japanese Longitudinal Survey on Employment and Fertility (LOSEF). LOSEF is administered as a project of the Economic Analysis of Intergenerational Issues (Principal Investigator: Noriyuki Takayama), which is funded through the Grant-in-Aid for Specially Promoted Research from Japan's Ministry of Education, Culture, Sports, Science and Technology. With the collaboration of Intage, Inc., a pilot survey was administered in February 2012, followed by the first survey, conducted between September and October 2012. The survey targeted men and women between 20 and 49 years of age living in Japan. The survey respondents, chosen from among the individuals publicly recruited by Intage, Inc., were randomly stratified based on (1) age, gender, and regional information from the 2010 Census, and (2) the employment-to-nonemployment ratio from the Employment Status Survey 2007 (ESS). A screening survey was first conducted on a random sample of 12,000 individuals to inquire about their willingness to participate in the survey, with 7,282 individuals indicating their willingness. From this pool of 7,282, mail questionnaires were then sent to 5,000 randomly selected individuals, resulting in 4,787 responses. A total of 2,114 responses was also obtained in the pilot survey using the same method. ${ }^{1}$ The total number of samples, combining those from the pilot survey and from the first survey, stands at 6,901 respondents. Since the sample consists of individuals recruited by Intage, Inc., the sample is not necessarily a nationally representative sample of the Japanese population. We restrict our sample to respondents who have at least one child, with the result that our sample consists of 3,651 parents and 7,148 children.

Two measures of breastfeeding practices are used: (1) breastfeeding initiation, and (2) breastfeeding duration, which is the number of months that the mother breastfed the child if she had ever breastfed the child. The measure of breastfeeding

\footnotetext{
1 Specifically, in the pilot survey, the mail questionnaires were sent to 2,558 respondents, resulting in 2,114 responses. The purpose of the pilot survey was to examine how respondents would answer the questionnaires and to make any necessary changes for the first survey. However, for the variables used in the paper, the wording of the two questionnaires is identical.
} 
initiation is set to one for those who answered yes to "Did you breastfeed your child?" and zero for those who answered no. For those who answered yes, the duration of breastfeeding is asked for: "Until when did you (or your spouse) breastfeed your child? This applies not only to exclusive breastfeeding but also mixed feeding (i.e., using a combination of breastfeeding and bottle feeding)." Therefore, breastfeeding is defined as any breastfeeding, not necessarily exclusive breastfeeding (Japan Pediatric Society 2011). The survey asked about breastfeeding practices for each of the respondents' children.

LOSEF also collected information on changes in the employment status and job responsibility of mothers and fathers before and after each child's birth, adapted from the questionnaires used by Goldin and Katz (2008). The wording of the question regarding changes in employment status is: "1 year after the birth of your child, how did your (or your spouse's) paid employment status change relative to 1 year before?" The respondents were asked to choose one of the following: (1) not employed before or after, (2) left employment, (3) working fewer hours, (4) working the same hours, (5) working more hours, and (6) started working. The wording of the question regarding changes in job responsibilities is: " 1 year after the birth of your child, how did your (or your spouse's) work responsibilities change relative to 1 year before?" The respondents were asked to mark all that apply from the following choices: (1) more responsibility, (2) work under flextime system, (3) more hours for pay at home, (4) traveling less for work, (5) no change, (6) other, and (7) not working. In Japan's flextime systems, workers separate their workday into hours that they must work ("core time," usually between 10 a.m. and 3 p.m.) and hours from which they can choose to work ("flexible time").

Since only $4.3 \%$ of fathers were not working 1 year after their child's birth, we estimate the effects of the change in fathers' job responsibilities on breastfeeding initiation and duration. In contrast, since $75 \%$ of mothers were not working 1 year after childbirth, we estimate the effects of change in mothers' employment status. Descriptions of the variables used in this paper are presented in Table 1, along with the variable means and standard deviations.

\subsection{Breastfeeding variables}

In LOSEF, $86.1 \%$ of the sample initiated breastfeeding, and among those who initiated breastfeeding, the average duration of breastfeeding is 14.56 months (see Table 1). Figure 1 presents the distribution of duration of breastfeeding for those who initiated breastfeeding. We find that $7.9 \%$ of the sample breastfed for 6 months, $28.7 \%$ breastfed for 12 months, and $9.1 \%$ breastfed for 2 years.

These numbers from LOSEF are in line with other statistics available in Japan on breastfeeding. A survey conducted by Nakada (2008) with 404 samples reports the average breastfeeding duration as 1 year and 4 months, and the mode as 1 year. The rate of breastfeeding is $86.8 \%$ at 3 months in the 2010 National Growth Survey on Infants and Preschool Children (Ministry of Health, Labour and Welfare 2011), while in our sample $85.13 \%$ of children are breastfed at 3 months. The rate of breastfeeding is $72.7 \%$ at 6 months in the 2001 Longitudinal Survey of Babies in Twenty-first Century (Kaneko et al. 2006), while in our sample $76.0 \%$ of children 
Table 1 Variable descriptions and descriptive statistics

\begin{tabular}{|c|c|c|c|}
\hline Variable & Description & Mean & SD \\
\hline Breastfeeding initiation & Dummy variable $=1$ if the child was breastfed & 0.861 & 0.346 \\
\hline Breastfeeding duration & $\begin{array}{l}\text { Number of months that mother breastfed the child if she ever } \\
\text { breastfed the child }\end{array}$ & 14.56 & 9.535 \\
\hline \multicolumn{4}{|l|}{ Child's characteristics } \\
\hline Child is first born & Dummy variable $=1$ if child is first born & 0.508 & 0.500 \\
\hline Female child & Dummy variable $=1$ if child is female & 0.487 & 0.500 \\
\hline Low birth-weight & Dummy variable $=1$ if child's birth weight is $2500 \mathrm{~g}$ or less & 0.082 & 0.275 \\
\hline Multiple birth & Dummy variable $=1$ if child is a multiple & 0.020 & 0.141 \\
\hline Two children & $\begin{array}{l}\text { Dummy variable }=1 \text { if number of children in household is } \\
\text { two }\end{array}$ & 0.531 & 0.499 \\
\hline $\begin{array}{l}\text { More than three } \\
\text { children }\end{array}$ & $\begin{array}{l}\text { Dummy variable }=1 \text { if number of children in household is } \\
\text { three or more }\end{array}$ & 0.334 & 0.472 \\
\hline \multicolumn{4}{|l|}{ Maternal characteristics } \\
\hline Mother's age & Mother's age in year child was born & 29.03 & 4.402 \\
\hline Less than high school & $\begin{array}{l}\text { Dummy variable }=1 \text { if mother has less than high school } \\
\text { education }\end{array}$ & 0.029 & 0.169 \\
\hline High school & Dummy variable $=1$ if mother is a high school graduate & 0.379 & 0.485 \\
\hline Junior college & Dummy variable $=1$ if mother is a junior college graduate & 0.386 & 0.487 \\
\hline $\begin{array}{l}\text { More than college } \\
\text { education }\end{array}$ & $\begin{array}{l}\text { Dummy variable }=1 \text { if mother has more than four year } \\
\text { college education }\end{array}$ & 0.206 & 0.404 \\
\hline Mother born in $1950 \mathrm{~s}$ & Dummy variable $=1$ if mother was born in the $1950 \mathrm{~s}$ & 0.002 & 0.043 \\
\hline Mother born in $1960 \mathrm{~s}$ & Dummy variable $=1$ if mother was born in the 1960 s & 0.380 & 0.486 \\
\hline Mother born in $1970 \mathrm{~s}$ & Dummy variable $=1$ if mother was born in the $1970 \mathrm{~s}$ & 0.488 & 0.500 \\
\hline Mother born in $1980 \mathrm{~s}$ & Dummy variable $=1$ if mother was born in the $1980 \mathrm{~s}$ & 0.127 & 0.332 \\
\hline Mother born in 1990s & Dummy variable $=1$ if mother was born in the $1990 \mathrm{~s}$ & 0.003 & 0.052 \\
\hline \multicolumn{4}{|c|}{ Mother's change in employment status } \\
\hline $\begin{array}{l}\text { Not employed before } \\
\text { or after }\end{array}$ & $\begin{array}{l}\text { Dummy variable }=1 \text { if mother was not employed before or } \\
\text { after childbirth }\end{array}$ & 0.643 & 0.479 \\
\hline Left employment & $\begin{array}{l}\text { Dummy variable }=1 \text { if mother left employment after } \\
\text { childbirth }\end{array}$ & 0.108 & 0.310 \\
\hline $\begin{array}{l}\text { Employed, working } \\
\text { fewer hours }\end{array}$ & $\begin{array}{l}\text { Dummy variable }=1 \text { if mother worked fewer hours after } \\
\text { childbirth }\end{array}$ & 0.064 & 0.244 \\
\hline $\begin{array}{l}\text { Employed, working } \\
\text { same hours }\end{array}$ & $\begin{array}{l}\text { Dummy variable }=1 \text { if mother worked same hours after } \\
\text { childbirth }\end{array}$ & 0.133 & 0.339 \\
\hline $\begin{array}{l}\text { Employed, working } \\
\text { more hours }\end{array}$ & $\begin{array}{l}\text { Dummy variable }=1 \text { if mother worked more hours after } \\
\text { childbirth }\end{array}$ & 0.008 & 0.087 \\
\hline $\begin{array}{l}\text { Employed, returned to } \\
\text { work }\end{array}$ & $\begin{array}{l}\text { Dummy variable }=1 \text { if mother worked fewer, same, or } \\
\text { more hours after childbirth }\end{array}$ & 0.204 & 0.403 \\
\hline Started working & $\begin{array}{l}\text { Dummy variable }=1 \text { if mother started working after } \\
\text { childbirth }\end{array}$ & 0.045 & 0.207 \\
\hline \multicolumn{4}{|c|}{ Father's change in job responsibility (mark all items that apply) } \\
\hline More responsibility & $\begin{array}{l}\text { Dummy variable }=1 \text { if father has more job responsibility } \\
\text { after childbirth }\end{array}$ & 0.253 & 0.435 \\
\hline
\end{tabular}


Table 1 continued

\begin{tabular}{|c|c|c|c|}
\hline Variable & Description & Mean & SD \\
\hline $\begin{array}{l}\text { Work under flextime } \\
\text { system }\end{array}$ & $\begin{array}{l}\text { Dummy variable }=1 \text { if father worked under flextime } \\
\text { system after childbirth }\end{array}$ & 0.021 & 0.143 \\
\hline $\begin{array}{l}\text { More hours for pay at } \\
\text { home }\end{array}$ & $\begin{array}{l}\text { Dummy variable }=1 \text { if father worked more hours for pay at } \\
\text { home after childbirth }\end{array}$ & 0.007 & 0.082 \\
\hline Travel less for work & $\begin{array}{l}\text { Dummy variable }=1 \text { if father traveled less for work after } \\
\text { childbirth }\end{array}$ & 0.008 & 0.089 \\
\hline No change & $\begin{array}{l}\text { Dummy variable }=1 \text { if father's job responsibility did not } \\
\text { change after childbirth }\end{array}$ & 0.655 & 0.475 \\
\hline Other & $\begin{array}{l}\text { Dummy variable }=1 \text { if there was other change in father's } \\
\text { job responsibility }\end{array}$ & 0.013 & 0.115 \\
\hline Not working & $\begin{array}{l}\text { Dummy variable }=1 \text { if father was not working before and/ } \\
\text { or after childbirth }\end{array}$ & 0.043 & 0.203 \\
\hline
\end{tabular}

are breastfed at 6 months. In the US, among babies born in 2009, the rate of infants ever breastfed is $76.5 \%$ and the rate of breastfeeding at 6 months of age is $49.0 \%$ (Centers for Disease Control and Prevention 2013); the median duration of breastfeeding is 38.7 weeks (approximately 9.675 months) according to Fein et al. (2008). These statistics reveal that breastfeeding initiation is higher and breastfeeding duration is longer in Japan than in the US. One reason for this difference in breastfeeding behavior may be the fact that postpartum hospital stays provide women with the opportunity to receive breastfeeding support-and the hospital stay after delivery is longer in Japan than in the US. Specifically, in Japan, the typical stay in the hospital after delivery is 5-8 days (Katsukawa et al. 2010), while most women are discharged from the US hospitals between 24 and $72 \mathrm{~h}$ after delivery (American Academy of Pediatrics 2005). Since only $55 \%$ of US mothers receive breastfeeding support after being discharged from the hospital (Lewallen et al. 2006), it is likely that many women in the US leave the hospital before being able to produce enough breast milk (American Academy of Pediatrics 2005). Another reason for this difference in breastfeeding behavior between Japan and the US is because the maternity leave system is more generous in Japan than in the US. Specifically, in Japan, mothers are guaranteed 8 weeks of post-childbirth maternity leave, and either the mother or the father has access to child care leave until the child's first birthday. A worker of either gender on leave is entitled to a child-care leave allowance which is $50 \%$ of their regular monthly wages earned before taking leave. In contrast, under the US Family and Medical Leave Act, only employees working at companies with more than fifty employees are eligible for 12 weeks of leave-and that leave is unpaid. ${ }^{2}$

\footnotetext{
${ }^{2}$ Because the number of working women who have infant children is much smaller in Japan than in the US, far fewer women in Japan report returning to work as a difficulty in breastfeeding. Specifically, among mothers in Japan who stopped breastfeeding during the first month after childbirth, $63.8 \%$ report "insufficient milk supply," whereas only $0.8 \%$ report "returning to work" (Ministry of Health, Labour and Welfare 2005). In contrast, in the US, among mothers who report a reason for ceasing to breastfeed during the first month after childbirth, $38.8 \%$ report "insufficient milk supply," whereas $14.2 \%$ report "returning to work/school" (Ahluwalia et al. 2005).
} 


\subsection{Methods}

In the next section, we estimate the following model: $Y_{i m}=\beta X_{i m}+\omega_{m}+\epsilon_{i m}$, where $i$ denotes child, $m$ mother, $Y_{i m}$ the variable indicating breastfeeding practices, $X_{i m}$ the vector of covariates including an intercept, $\beta$ the coefficients for the covariates, $\omega_{m}$ the mother fixed-effects, and $\epsilon_{i m}$ the error term. The covariates $X_{i m}$ include: child's characteristics (sex, low birth-weight, multiple births, firstborn, and number of siblings), maternal characteristics (age at birth of the child, education, and birth cohort by decade), and changes in maternal employment and paternal job responsibility before and after childbirth. To deal with the correlation between maternal employment and unobserved maternal characteristics $\omega_{m}$, we also estimate mother fixed-effects models. With this method, we can control for any unobserved mother fixed-effects, but we cannot account for reverse causality or other forms of endogeneity. ${ }^{3}$

\section{Results}

\subsection{Breastfeeding initiation}

Table 2, Column 1 presents the odds ratios and $95 \%$ confidence intervals for the logit model of breastfeeding initiation on the child's characteristics, maternal characteristics, and changes in maternal and paternal job responsibility before and after childbirth. In Table 2, Column 2, we present results that combine into one category mothers who work (1) fewer hours 1 year after childbirth, (2) the same hours 1 year after childbirth, or (3) more hours 1 year after childbirth; that is, this one category consists of all mothers who return to work within a year after childbirth. The results from the mother fixed-effects logit model presented in Table 2, Column 3 use the same specification as in Table 2, Column 2.

Table 2, Column 1 shows that, when compared with the odds for mothers who graduated from high school, the odds of breastfeeding are 0.619 times lower for those with less than high school education, 1.591 times higher for those with junior college education, and 2.127 times higher for those with more than college education. A 1-year increase in maternal age in the year that the child was born increases the odds of breastfeeding by $6.1 \%$. This pattern of more highly educated mothers and older mothers being more likely to initiate breastfeeding is consistent with findings from studies in the US and the UK (e.g., Chatterji and Frick 2005; Lindberg 1996; Noble et al. 2001; Ryan et al. 2006). This positive association between education and breastfeeding initiation is partly because women tend to obtain information about breastfeeding from written materials, and therefore, women at higher literacy levels are more likely to have developed better

\footnotetext{
${ }^{3}$ Specifically, the fixed-effects approach is used to rule out time-invariant mother fixed-effects on the observed relationship between maternal employment and breastfeeding practices. However, this approach cannot account for time-variant unobserved mother characteristics nor another important source of endogeneity-reverse causality — which implies that breastfeeding practices might exert a causal effect on maternal employment, in addition to the effect of maternal employment on breastfeeding practices.
} 


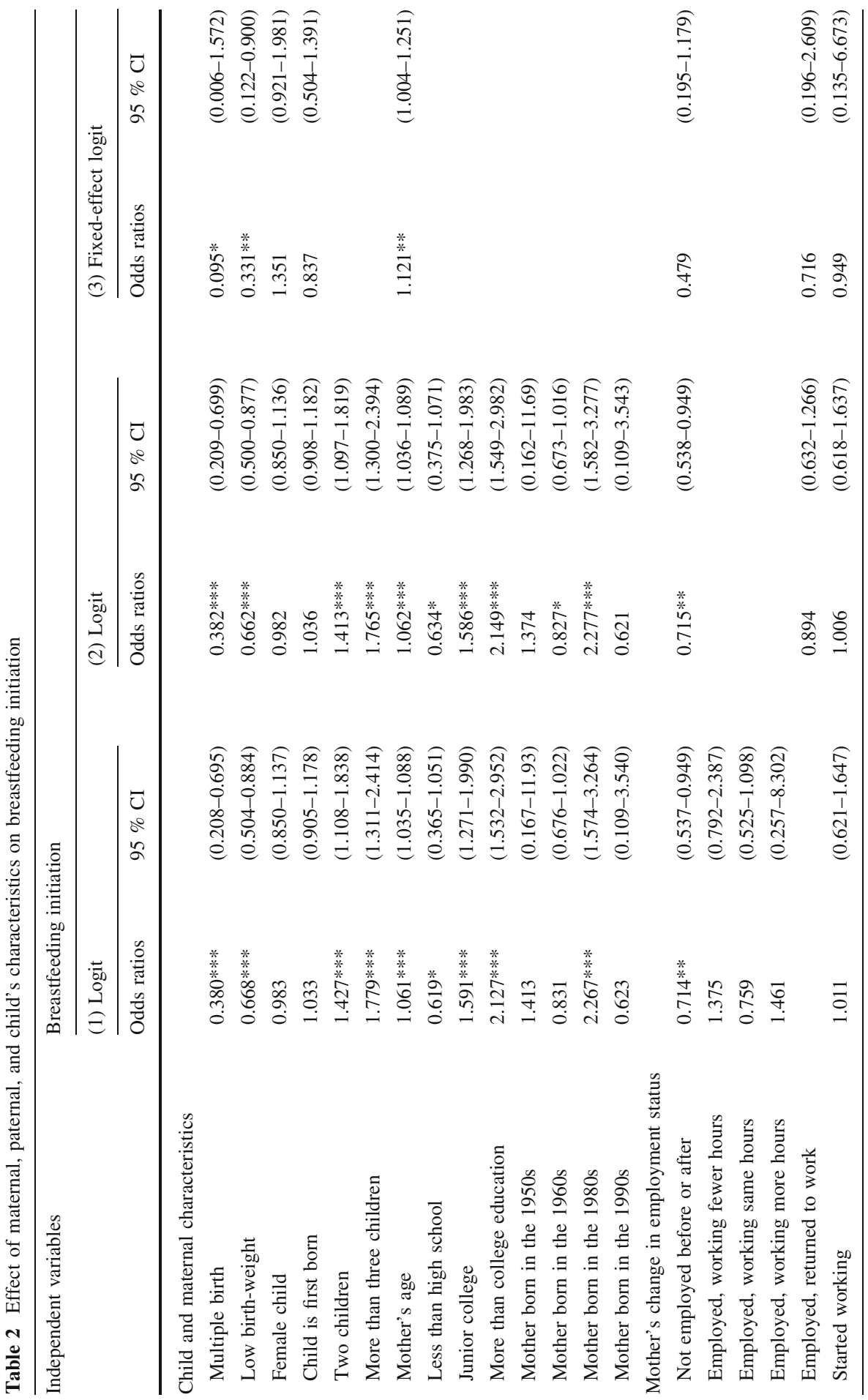




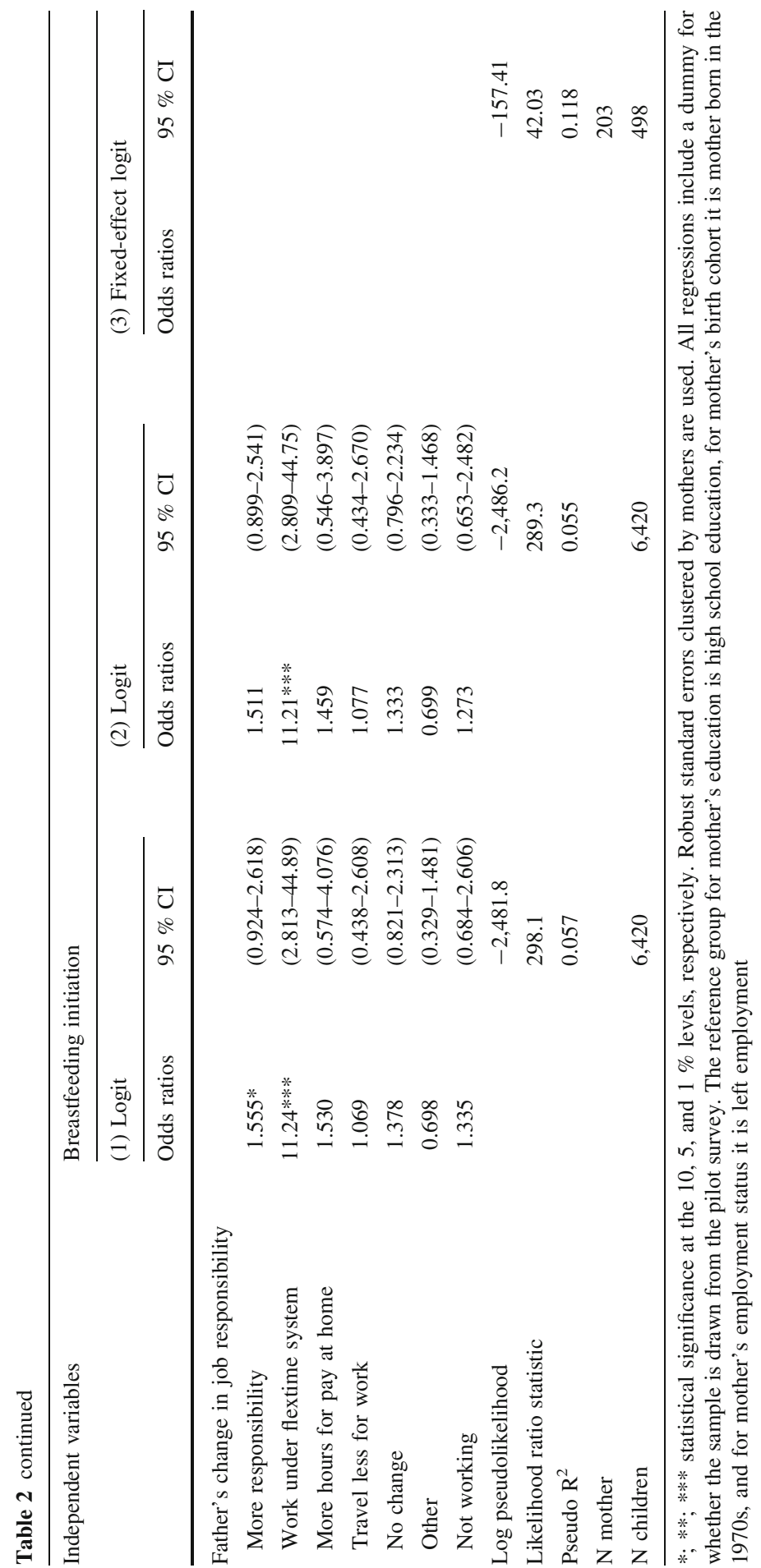


breastfeeding skills than women at lower literacy levels (Kaufman et al. 2001; Lewallen et al. 2006).

Two other relevant factors that affect the odds of breastfeeding are (1) the baby's birth weight, and (2) multiple births. Having a low birth-weight infant decreases the odds of breastfeeding by $33.2 \%$, because such infants tend to be kept in incubators, to be too weak to suckle, and to be hospitalized longer, compared to infants of normal birth weight (Ooki 2008). The odds of breastfeeding are also 0.380 times lower for multiple births, compared to single births. Using the Longitudinal Survey of Babies in the Twenty-first Century, Kaneko et al. (2006) examine factors associated with exclusive breastfeeding during the first 6 months of life in Japan and find that low birth-weight and multiple births are negatively associated with exclusive breastfeeding. Similarly, Yokoyama et al. (2006) use a database of medical check-ups of infants aged 3-6 months in Nishinomiya City in Japan, and also find that mothers who give birth to multiples are more likely to bottle-feed with only formula milk than those who had singletons.

Compared with mothers born in the 1970s, mothers born in the 1960s have 0.831 times lower odds of breastfeeding, whereas those born in the 1980s have 2.267 times higher odds of breastfeeding. Therefore, mothers from later generations are more likely to breastfeed their children, perhaps because the time they began motherhood overlaps with the time when WHO started promoting breastfeeding and they were informed of the benefits of breastfeeding for both mothers and children.

To investigate the effect of maternal employment on breastfeeding initiation, we look at the odds ratio from the mother fixed-effects logit model in Table 2, Column 3 . Note that when the fixed-effects model is estimated, the sample is reduced from 6,420 to 498 , because only $6.2 \%$ of mothers who have more than one child vary the way they feed their infant depending on the child. Compared to mothers who leave employment after childbirth, the odds of mothers who return to work within a year after childbirth to initiate breastfeeding are 0.716 times lower, but this is not statistically significant (Table 2, Column 3). This result is in contrast to that of Chatterji and Frick (2005); using the US National Longitudinal Survey of Youth 1979 (NLSY1979), they also estimate a mother fixed-effects model and find that for US women, returning to work within 3 months is associated with a reduction of $16-17 \%$ in the probability that the mother will initiate breastfeeding. Therefore, initiation of breastfeeding and maternal employment appear to be more compatible in Japan than in the US ${ }^{4}$.

In the mother fixed-effects logit model, among the 203 mothers who have multiple children and change their method of infant feeding according to the child, few of their spouses change their job responsibility according to the child; as a result, the effect of the fathers' job-responsibility variables cannot be assessed. We

\footnotetext{
4 The odds-ratio for the variable on mothers who were not employed either before or after childbirth is significant in the logit model but no longer significant in the fixed-effect logit model. Since mothers who were not employed either before or after childbirth are likely to be less educated, the omitted-variable bias may be one reason for this difference in estimates between the logit and fixed-effect logit models.
} 


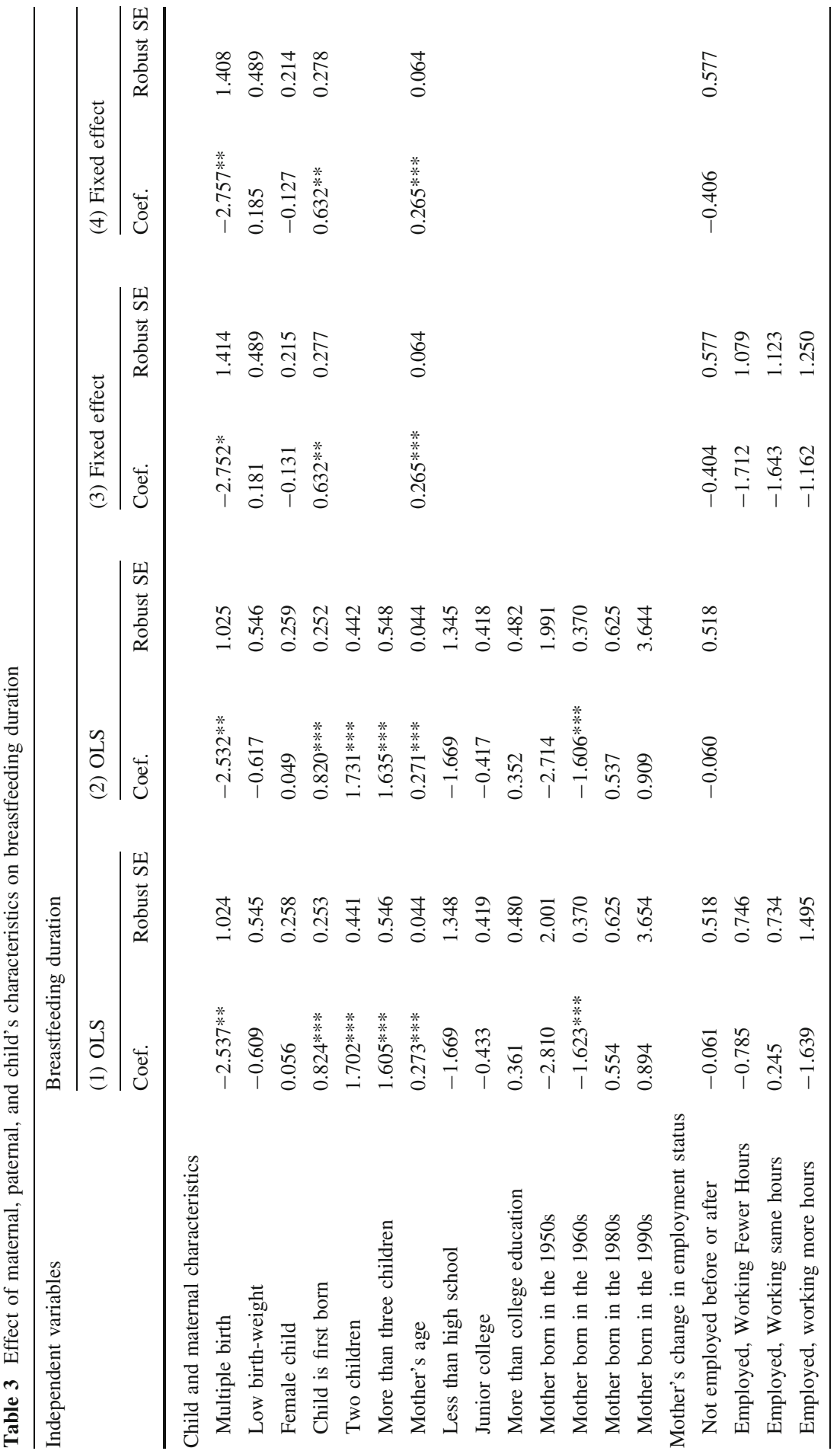




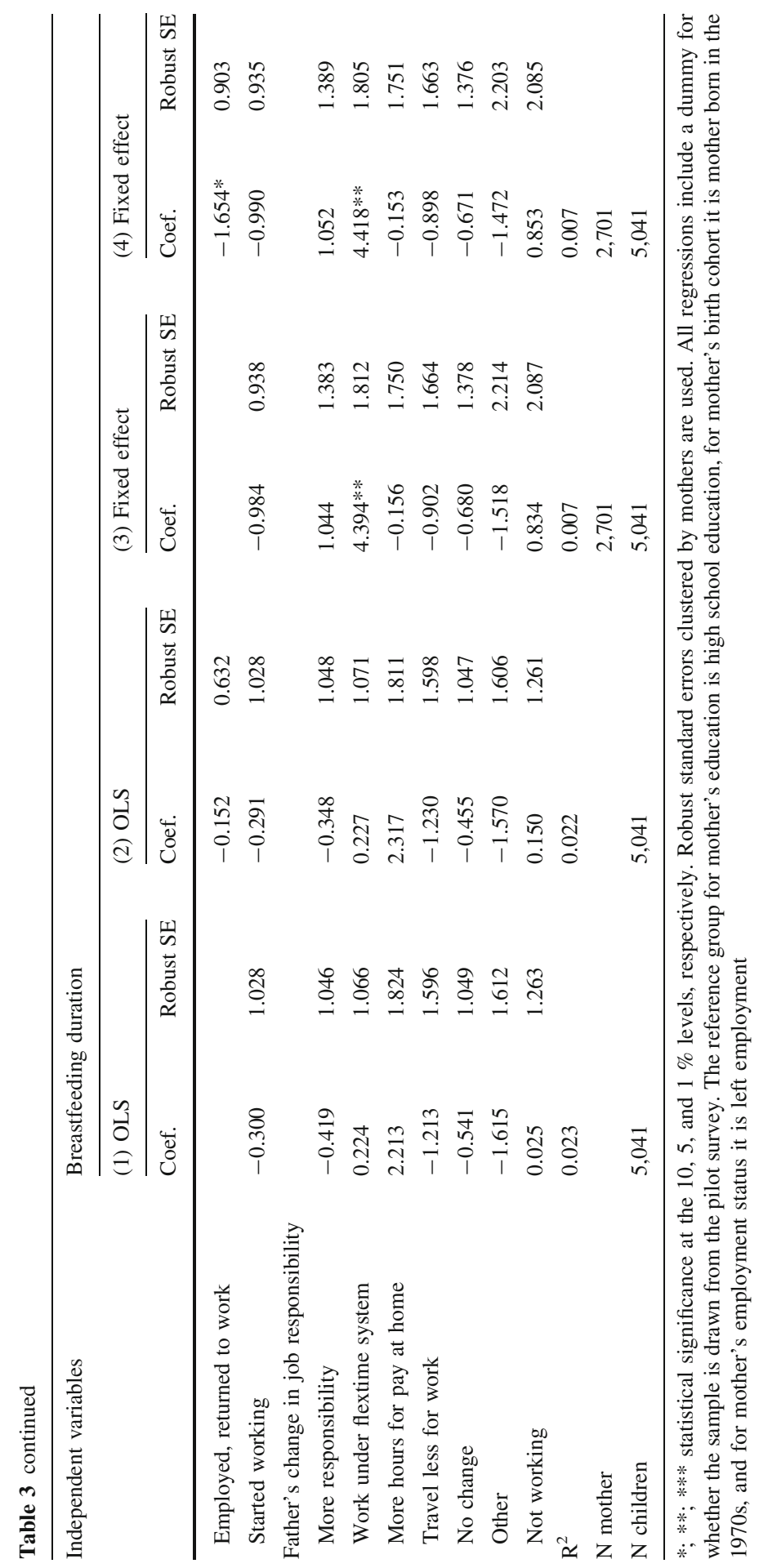


thus drop the fathers' job-responsibility variables from the regression. ${ }^{5}$ We therefore focus on estimates from the logit model for estimates on how the fathers' jobresponsibility variables affect breastfeeding initiation. We find that the odds of breastfeeding are 11.21 times higher for a mother whose spouse works under the flextime system after childbirth. Although this effect is certainly substantial, we cannot confirm that the relationship between fathers' job responsibility and breastfeeding initiation is a causal one.

\subsection{Duration of breastfeeding}

We now turn to examine the factors associated with the duration of breastfeeding. The OLS estimates are reported in Table 3, Columns 1 and 2, and the fixed-effects estimates are reported in Table 3, Columns 3 and 4 . The specification in Columns 1 and 3 includes information on whether mothers work fewer hours, work the same hours, or work more hours as the covariates on maternal employment, whereas the specification in Columns 2 and 4 combines them and uses information on whether mothers return to work after childbirth.

Although more highly educated mothers are more likely to initiate breastfeeding, the levels of maternal education make only a small and insignificant difference in breastfeeding duration for mothers who do breastfeed. Highly educated mothers, who are more likely to have high health literacy, typically do initiate breastfeeding, but once breastfeeding is initiated, other factors (such as maternal age and the presence of siblings) affect the duration of breastfeeding. This result is different from the findings in the US reported by Roe et al. (1999) and Chatterji and Frick (2005); these papers indicate that highly educated mothers not only are more likely to breastfeed, but also breastfeed longer when they do breastfeed.

The duration of breastfeeding decreases by 2.537 months for mothers who give birth to multiples compared to those who give birth to a singleton. Mothers of multiples have difficulty continuing breastfeeding because nursing multiples takes more time, which can lead to the mothers being more exhausted, and their milk supply is sometimes insufficient to nurse multiples (Leonard 2003; Ooki 2008). The duration of breastfeeding for mothers born in the 1960s is shorter by a significant 1.623 months than for those born in the 1970s. Each one-year increase in the mother's age at the time of childbirth increases the duration of breastfeeding by 0.273 months. ${ }^{6}$ Therefore, mothers who give birth to multiples, mothers from earlier generations, and mothers who give birth at a younger age have reduced breastfeeding initiation and duration. On the other hand, low-birth-weight infants decrease the incidence of breastfeeding but their breastfeeding duration is about the same as for normal-weight infants. This implies that once mothers who are able to

\footnotetext{
5 Among the 203 mothers, the within variation for the father's job-responsibility variables is particularly small. Specifically, the within variation is zero for "more hours for pay at home," 0.032 for "work under flextime system," 0.045 for "travel less for work," and 0.079 for "other," and 0.048 for "not working.".

6 Previous studies have also found that maternal age is positively associated with the initiation and the duration of breastfeeding. Haughton et al. (2010) argue that older women may have had more opportunities to receive information about breastfeeding and how to overcome breastfeeding difficulties.
} 
initiate breastfeeding with their low-birth-weight infants, they are able to continue to breastfeed just as normally as with their normal-weight-infants.

Although the odds of a Japanese child's being breastfed do not differ by birth order, the duration of breastfeeding is 0.824 months longer for firstborns than for subsequent children. In contrast, the findings based on the US NLSY1979 that are reported in Lehmann et al. (2013) show no clear patterns in the relationship between the duration of breastfeeding and birth order; however, the mothers were 10-14\% less likely to breastfeed their younger children compared to firstborns. When the family includes older siblings, mothers tend to have less time to devote to caring for each child (Lawrence 2010). In Japan, this result in shorter duration of breastfeeding for the younger children, while in the US the result is a lower probability of any breastfeeding for the younger child. Because Price (2008) finds that a first-born child receives 20-30 more minutes of quality time each day with his or her parent than a second-born child of the same age from a similar family, it should not come as a surprise that the time spent breastfeeding a first-born child may be longer than for a later-born child.

To investigate the effect of maternal employment on the duration of breastfeeding, we look at the mother fixed-effects results. ${ }^{7}$ Compared to mothers who leave employment after childbirth, mothers who work less after childbirth breastfeed for 1.712 fewer months, those who work the same hours for 1.643 fewer months, and those who work more hours for 1.162 fewer months, although the estimates are all insignificant (Table 3, Column 3). In Table 3, Column 4, we pool mothers who work the same, less, or more hours and categorize them all as mothers who return to work after childbirth. Compared to mothers who left employment after childbirth, mothers who return to work after childbirth breastfeed for 1.654 (standard error 0.903) fewer months. The decreasing effect of maternal employment on breastfeeding duration is significant at the $10 \%$ level.

On the other hand, the duration of breastfeeding is longer by 4.418 months for mothers whose spouses work under a flextime system after childbirth, compared to mothers whose spouses do not change to such a system (Table 3, Column 4). This result suggests that fathers' increased participation in childcare results in mothers having more time to breastfeed their children.

\section{Conclusion}

This paper examines the factors that influence breastfeeding initiation and duration. Since few studies have thus far investigated the relationship between breastfeeding duration and mothers' socioeconomic status (Inoue et al. 2012), this paper reveals new evidence regarding breastfeeding practices in Japan.

Breastfeeding tends to be initiated by mothers with a higher level of education, but once initiated, breastfeeding duration does not differ significantly by mothers' education. Breastfeeding initiation does not differ by the child's birth order, but its

\footnotetext{
${ }^{7}$ Note that the fixed-effect estimates essentially drop mother from the regression mothers who have only one child.
} 
duration tends to be longer for the firstborn child than younger ones. Both breastfeeding initiation and duration are greater for mothers who give birth to a singleton, for mothers from later generations, and for mothers who give birth to a child at an older age. Compared to mothers who left employment after childbirth, mothers who return to work within a year after childbirth have about 1.654 shorter months of breastfeeding duration, although there is no significant difference in breastfeeding initiation. When fathers work under a flextime system after childbirth, the odds of breastfeeding initiation increases and the duration of breastfeeding is prolonged. These results suggest that supporting fathers to work flextime can promote breastfeeding in Japan.

This last point has an important implication for employment policies, since this result suggests that employment policies that grant a flextime system for fathers will be effective in promoting breastfeeding practices. To date, policies for parenting support in Japan focus on increasing the take-up rate of paternity leave, since only $1.89 \%$ of the male labor force takes paternity leave (Ministry of Health, Labour and Welfare 2012). ${ }^{8}$ This low take-up rate implies that it is difficult for fathers to take time off completely from work after childbirth; therefore, providing a flextime system for them-which is less costly and more easily adoptable for both the firm and the worker-may be a more realistic second-best option for supporting working families in Japan.

Acknowledgments This paper is part of an academic project called "Economic Analysis of Intergenerational Issues: Searching for Further Development," funded by a Grant-in-Aid for Specially Promoted Research from Japan's Ministry of Education, Culture, Sports, Science and Technology (Grant Number 22000001).

Open Access This article is distributed under the terms of the Creative Commons Attribution License which permits any use, distribution, and reproduction in any medium, provided the original author(s) and the source are credited.

\section{References}

Ahluwalia, I. B., Morrow, B., \& Hsia, J. (2005). Why do women stop breastfeeding? Findings from the pregnancy risk assessment and monitoring system. Pediatrics, 116(6), 1408-1412.

American Academy of Pediatrics. (2005). Breastfeeding handbook for physicians. Elk Grove Village: American Academy of Pediatrics.

Baker, M., \& Milligan, K. (2008). Maternal employment, breastfeeding, and health: Evidence from maternity leave mandates. Journal of Health Economics, 27(4), 871-887.

Beral, V., Bull, D., Doll, R., Peto, R., \& Reeves, G. (2002). Breast cancer and breastfeeding: Collaborative reanalysis of individual data from 47 epidemiological studies in 30 countries, including 50,302 women with breast cancer and 96,973 women without the disease. Lancet, $360(20), 187-195$.

\footnotetext{
${ }^{8}$ While $83.6 \%$ of the female labor force takes maternity leave, this low take-up rate in the case of Japanese fathers is because their long working hours and heavy workloads usually make it much harder for them than for mothers to actually use the system by taking the leave. In particular, male workers in their $30 \mathrm{~s}$ are afraid to take the leave because it could burden their bosses and colleagues and therefore hurt their careers (Sato and Takeishi 2004).
} 
Borra, C., Iacovou, M., \& Sevilla, A. (2012). The Effect of breastfeeding on children's cognitive and noncognitive development. Labour Economics, 19(4), 496-515.

Cabinet Office, Government of Japan. (2012). White paper on Birthrate-Declining Society. Tokyo: Cabinet Office, Government of Japan. (in Japanese).

Centers for Disease Control and Prevention. (2013). Breastfeeding Report Card United States. Atlanta: Centers for Diseases Control and Prevention.

Chatterji, P., \& Frick, K. D. (2005). Does returning to work after childbirth affect breastfeeding practices? Review of Economics of the Household, 3(3), 315-335.

Cooklin, A. R., Donath, S. M., \& Amir, L. H. (2008). Maternal employment and breastfeeding: Results from the longitudinal study of Australian children. Acta Padiatrica, 97(5), 620-623.

Fein, S. B., Mandal, B., \& Roe, B. E. (2008). Success of strategies for combining employment and breastfeeding. Pediatrics, 122, S56-S62.

Gatrell, C. J. (2007). Secrets and lies: Breastfeeding and professional paid work. Social Science and Medicine, 65(2), 393-404.

Goldin, C., \& Katz, L. F. (2008). Transitions: Career and family life cycles of the educational elite. American Economic Review, 98(2), 363-369.

Haider, S. J., Jacknowitz, A., \& Schoeni, R. F. (2003). Welfare work requirements and child well-being: Evidence from the effects on breast-feeding. Demography, 40(3), 479-497.

Haughton, J., Gregorio, D., \& Perez-Escamilla, R. (2010). Factors associated with breastfeeding duration among Connecticut special supplemental nutrition program for women, infants, and children (WIC) participants. Journal of Human Lactation, 26(3), 266-273.

Howie, P. W., Forsyth, J. S., Ogston, S. A., Clark, A., \& Florey, C. D. (1990). Protective effect of breastfeeding against infection. British Medical Journal, 300(6716), 11-16.

Inoue, M., Binns, C. W., Otsuka, K., Jimba, M., \& Matsubara, M. (2012). Infant feeding practices and breastfeeding duration in Japan: A review. International Breastfeeding Journal, 7(1), 1-15.

Ip, S., Chung, M., Raman, G., Chew, P., Magula, N., DeVine, D., et al. (2007). Breastfeeding and maternal and infant health outcomes in developed countries. Evidence Report Technology Assessment, 153, 1-415.

Japan Pediatric Society Nutrition Committee and Neonatal Committee. (2011). Pediatrician and breast feeding promotion. The Journal of Japanese Pediatric Society, 115(8), 1363-1389. (in Japanese).

Kaneko, A., Kaneita, Y., Yokoyama, E., Miyake, T., Harano, S., Suzuki, K., et al. (2006). Factors associated with exclusive breast-feeding in Japan: For activities to support child-rearing with breastfeeding. Journal of Epidemiology., 16(2), 57-63.

Katsukawa, Y., Sakanashi, K., Usui, M., \& Kobayashi, M. (2010). Sanjoku nyuin no genjo to nyuinkikantanshukuka no jouken (Conditions of contemporary postpartum hospital stays and how to reduce their duration: Results from a nationwide survey). The Japanese Journal for Midwives, 64(4), 302-306. (in Japanese).

Kaufman, H., Skipper, B., Small, L., Terry, T., \& McGrew, M. (2001). Effect of literacy on breastfeeding outcomes. Southern Medical Journal, 94(3), 293-296.

Lawrence, R. A. (2010). Breastfeeding: A guide for the medical profession (7th ed.). St. Louis: Elsevier Health Sciences.

Lehmann, J.K., Nuevo-Chiquero, A. \& Vidal-Fernandez, M. (2013). Birth order differences in early inputs and outcomes. Unpublished manuscript, Department of Economics, University of Houston.

Leonard, L. G. (2003). Breastfeeding rights of multiple birth families and guidelines for health professionals. Twin Research, 6(1), 34-45.

Lewallen, L. P., Dick, M. J., Flowers, J., Powell, W., Zickefoose, K. T., Wall, Y. G., et al. (2006). Breastfeeding support and early cessation. Journal of Obstetric, Gynecologic, and Neonatal Nursing, 35(2), 166-172.

Lindberg, L. D. (1996). Women's decisions about breastfeeding and maternal employment. Journal of Marriage and the Family, 58(1), 239-251.

Mandal, B., Roe, B. E., \& Fein, S. B. (2010). The differential effects of full-time and part-time work status on breastfeeding. Health Policy, 97(1), 79-86.

Mandal, B., Roe, B.E., \& Fein, S.B. (2012). Work and breastfeeding decisions are jointly determined for higher socioeconomic status US mothers. Review of the Economics of the Household.

McCrory, C., \& Layte, R. (2011). The effect of breastfeeding on children's educational test scores at nine years of age: Results of an Irish cohort study. Social Science and Medicine, 75(9), 1515-1521.

McCrory, C., \& Layte, R. (2012). Breastfeeding and risk of overweight and obesity at nine years of age. Social Science and Medicine, 75(2), 323-330. 
Ministry of Health, Labour and Welfare. (2005). National Nutrition Survey on Infants and Preschool Children. Tokyo: Ministry of Health, Labour and Welfare.

Ministry of Health, Labour and Welfare. (2007). Junyu/rinyu no shien gaido (Guide to support breastfeeding and weaning) (in Japanese). Tokyo: Ministry of Health, Labour and Welfare.

Ministry of Health, Labour and Welfare. (2011). 2010 National Survey of Child Growth (in Japanese). Edited by Equal Employment, Children and Families Bureau. Tokyo: Ministry of Health, Labour and Welfare.

Ministry of Health, Labour and Welfare. (2012). Basic Survey of Gender Equality in Employment Management (in Japanese). Edited by Equal Employment Policy Division. Tokyo: Ministry of Health, Labour and Welfare.

Nakada, K. (2008). An analysis of maternal self-efficacy and breastfeeding continuation. Journal of Japan Academy of Midwifery, 22(2), 208-221. (in Japanese).

National Institute of Population and Social Security Research. (2010). Report on the Fourteenth Japanese National Fertility Survey in 2010 (in Japanese).

Noble, S., \& The ALSPAC Study Team. (2001). Maternal employment and the initiation of breastfeeding. Acta Padiatrica, 90, 423-428.

Ooki, S. (2008). Breast-feeding rates and related maternal and infants' obstetric factors in Japanese twins. Environmental Health and Preventive Medicine, 13, 187-197.

Price, J. (2008). Parent-child quality time: Does birth order matter? Journal of Human Resources, 43(1), 240-265.

Roe, B., Whittington, L. A., Fein, S. B., \& Teisl, M. F. (1999). Is there competition between breastfeeding and maternal employment? Demography, 36(2), 157-171.

Ryan, A. S., Zhou, W., \& Arensberg, M. B. (2006). The effect of employment status on breastfeeding in the United States. Women's Health Issues, 16(5), 243-251.

Sato, H., \& Takeishi, E. (2004). Dansei no ikuji kyugyo (Child care leave for men). Tokyo: Chuo Koronsha. (in Japanese).

WHO/UNICEF. (1990). Innocenti declaration on the protection, promotion and support of breastfeeding. http://www.unicef.org/programme/breastfeeding/innocenti.htm.

WHO/UNICEF. (2009). Baby-friendly hospital initiative: Revised, updated and expanded for integrated care. Geneva: World Health Organization.

Yokoyama, Y., Wada, S., Sugimoto, M., Katayama, M., Saito, M., \& Sono, J. (2006). Breastfeeding rates among singletons, twins and triplets in Japan: a population based study. Twin Research and Human Genetics., 9(2), 298-302. 